\title{
AÇÃO ANTI-HELMÍNTICA DO EXTRATO HIDROALCOÓLICO DE Alternanthera sessilis e Alternathera brasiliana EM OVINOS
}

\author{
Claudia Faccio Demarco' \\ Andressa Stein Maffi ${ }^{2}$ \\ Gabriela Bueno Luz $^{3}$ \\ Maria Amélia Agnes Weiller ${ }^{4}$ \\ Pedro Augusto Silva Silveira ${ }^{5}$ \\ Cristini Milech ${ }^{6}$ \\ Gustavo Sessa Fialho ${ }^{7}$
}

Resumo: Avaliou-se a atividade anti-helmíntica do extrato hidroalcoólico de plantas de Alternanthera sessilis e Alternanthera brasiliana em ovinos naturalmente infectados. Para o experimento foram utilizados 30 ovinos e estes foram distribuídos em 3 grupos: grupo 1: controle, que recebeu $10 \mathrm{~mL}$ de água, grupo 2: com $10 \mathrm{~mL}$ de solução com concentração de $500 \mathrm{mg} / \mathrm{L}$ de extrato de A. brasiliana e grupo 3: com $10 \mathrm{~mL}$ de solução com concentração de $500 \mathrm{mg} / \mathrm{L}$ de A. sessilis. Os animais receberam o tratamento por via oral durante os dias 1, 2, 3, 4 e 5 e as coletas de fezes para avaliar a carga parasitária foram realizadas nos dias 2, 3, 4, 5, e 7. Os resultados demonstraram que não houve diferença significativa na redução de ovos por grama de fezes, bem como na porcentagem de redução de OPG. Conclui-se que nas condições deste trabalho, os extratos não apresentaram ação anti-helmíntica em ovinos.

Palavras-chave: Resistência; Extrato hidroalcoólico; Plantas medicinais; Ovinocultura.

\footnotetext{
${ }^{1}$ Universidade Federal de Pelotas/Departamento Zootecnia, Brasil. E-mail: clau-demarco@hotmail.com.

2 Universidade Federal de Pelotas/Departamento Zootecnia, Brasil. E-mail: andressamaffi@gmail.com.

3 Universidade Federal de Pelotas/Departamento Zootecnia, Brasil. E-mail: gabrielabluz.veterinaria@gmail.com.

${ }^{4}$ Universidade Federal de Pelotas/Departamento Zootecnia, Brasil. E-mail: mariaamelia.weiller86@gmail.com.

5 Universidade Federal de Pelotas/Departamento de Clínica Veterinárias, Brasil. E-mail: pedrosilveira3@hotmail.com.

${ }^{6}$ Universidade Federal de Pelotas/Departamento de Botânica, Brasil. E-mail: crismilech.cm@gmail.com.

7 Universidade Federal de Pelotas/Departamento de Matemática e Estatística, Brasil. E-mail: gsfialho@hotmail.com.
} 